\title{
Conflict Analysis Based on Three-Way Decision Theoretic Fuzzy Rough Set over Two Universes
}

\author{
Xiao Tang ${ }^{1,2 *}$, Ting Zeng ${ }^{1,2}$, Yang Tan ${ }^{1,2}$, Benxiang Ding ${ }^{1,2}$ \\ ${ }^{1}$ School of Mathematical Sciences, Sichuan Normal University, Chengdu 610066, China \\ ${ }^{2}$ Institute of Intelligent Information and Quantum Information, Sichuan Normal University, Chengdu 610066, China
}

Corresponding Author Email: tang2007@sicnu.edu.cn

https://doi.org/10.18280/isi.250110

Received: 10 August 2019

Accepted: 19 November 2019

\section{Keywords:}

conflict information system (CIS), fuzzy rough set (FRS), conflict analysis, three-way decision, two universes

\begin{abstract}
Conflict is an inevitable feature of human endeavor. The conflict analysis has great theoretical and practical significance. Some scholars have discussed three-way decision in conflict analysis with probabilistic rough set (RS) over two universes, but have not probed deep into the fuzzy rough set (FRS) for conflict analysis. To make up for the gap, this paper firstly introduces the concepts and properties of conflict information system (CIS) and probabilistic CIS over two universes. Next, a brand-new system called FRS-CIS was established, followed by the construction of probability measure function and two novel mappings in the probabilistic FRS-CIS over two universes. Furthermore, the authors discussed the properties of probability measure and the lower and upper approximations of $Y$ with parameters $\alpha$ and $\beta$ corresponding to each mapping. Finally, $(0,1)$-probabilistic FRS and 0.5-probabilistic FRS were presented for the FRS-CIS and explained with examples, according to the three-way decision theoretic RS under the CIS over two universes. The research results shed new light to solving the FRS under FRS-CIS over two universes.
\end{abstract}

\section{INTRODUCTION}

Conflict is inevitable in many fields of human endeavor, namely, business and governmental negotiations, political and legal disputes, labor management, military operations, service and physical resources, commercial security policies, information decisions, water resource allocation, and risk control [1-14]. Therefore, it is very important to analyze and resolve conflicts in an accurate manner. So far, many models and methods have been developed for conflict analysis [2-7, $15,16,19-23]$.

Since the late 1990s, the rough set (RS) has been applied to conflict resolution and decision-making. Based on the RST, Z. Pawlak [4, 5] outlined a novel approach for conflict analysis. Later, various scholars have identified the limitations of Pawlak's conflict analysis model, and made many attempts to improve the model. First, Ramanna et al. [2] extended the RSbased conflict model to a complex conflict model. Next, Zhu and Wang [6] proposed the concept of associated conflict, and developed an approach for associated conflict analysis, using covering-based granular computing. Soon, Liu et al. [7] introduced a comprehensive strategy for associated conflict analysis through covering-based granular computing. Deja and Ślęak [16] described the nature of conflicts and several solutions to the fundamental problems of conflicts, and defined conflict situation models that clearly illustrate conflict components.

Pawlak's RS theory might be invalid if there are two or more correlated universes, such as investment plan [17] and medical diagnosis [18]. Despite their correlations, investor (sufferer) and project (symptom) belong to different universes. Therefore, it is necessary to promote RS-based conflict model to multiple universes. Drawing on the RS theory, B.Z. Sun et al. $[19,20]$ extended Pawlak's conflict analysis model to two universes, and also combined probabilistic rough set with three-way decision, creating a new conflict analysis model.

The RS-based conflict analysis is critical to decisionmaking. Lang et al. [21] presented the concepts of probabilistic conflict set, neutral set and allied conflict set, calculated the thresholds of conflict analysis with the decision theoretic RST, and designed incremental algorithms for the said sets in dynamic information system. With the aid of group decision theory, Lang et al. [22] also introduced methods to compute positive, neutral and negative alliances for conflicts in Pythagorean fuzzy information systems. Later, Lang et al. [23] proposed the concepts of agreement, disagreement and neutral subsets of a strategy with two evaluation functions, put forward a three-way decisions-based conflict analysis models to trisect the universe of agents, and employed a pair of twoway decisions models to interpret the mechanism of the threeway decision rules for an agent.

The fuzzy set (FS) and RS can effectively handle conflicts under uncertainty. So far, many have analyzed conflicts based on the RS or FS, but few have tackled conflict analysis from the perspective of FRS (FRS). To make up for this gap, this paper mainly investigates conflict analysis based on three-way decision FRS over two universes. Inspired by the RS-based decision rules proposed by Sun et al. [20] for conflict over two universes, the authors presented the decision rules for conflict based on the FRS over two universes, and then developed a three-way decision model of $(0,1)$-probabilistic FRS and 0.5probabilistic FRS.

The reminder of this paper is organized as follows: Section 2 reviews the CIS over two universes and introduces the FRS- 
CIS over two universes; Section 3 presents the three-way decision theoretic RS under the CIS over two universes, and illustrates the three-way decision models of $(0,1)$-probabilistic FRS and 0.5-probabilistic FRS with examples; Section 4 sums up the research findings.

\section{PRELIMINARIES}

This section introduces the concepts of the CIS and probabilistic CIS over two universes, and explains the lower and upper approximations of any feasible consensus strategy based on probabilistic CIS over two universes. In addition, the FRS-CIS and probabilistic FRS-CIS were defined over two universes, and the lower and upper approximations of any feasible consensus strategy were given under the probabilistic FRS-CIS over two universes.

\subsection{The CIS}

The Middle East conflict is a classic example of RST-based conflict analysis [3-5, 18, 21, 24]. The conflict involves six agents and five issues. The universe of agents can be expressed as $=\left\{u_{1}, u_{2}, u_{3}, u_{4}, u_{5}, u_{6}\right\}$, where $u_{1}-u_{6}$ are Israel, Egypt, Palestine, Jordan, Syria and Saudi Arabia, respectively; the universe of issues can be expressed as $V=\left\{a_{1}, a_{2}, a_{3}, a_{4}, a_{5}\right\}$, where $a_{1}-a_{5}$ are setting up an autonomous Palestinian state in the West Bank and Gaza, keeping the Israeli military outposts along the Jordan River, acknowledging Israeli occupation of East Jerusalem, keeping the Israeli military outposts on the Golan Heights, and granting citizenship to Palestinian refugees in Arab countries. The attitudes of each agent to the six issues can be summed up as the CIS in Table 1.

Table 1. The CIS of the Middle East conflict

\begin{tabular}{cccccc}
\hline $\boldsymbol{U} / \boldsymbol{V}$ & $\boldsymbol{a}_{1}$ & $\boldsymbol{a}_{2}$ & $\boldsymbol{a}_{3}$ & $\boldsymbol{a}_{4}$ & $\boldsymbol{a}_{5}$ \\
\hline $\boldsymbol{u}_{1}$ & - & + & + & + & + \\
$\boldsymbol{u}_{2}$ & + & 0 & - & - & - \\
$\boldsymbol{u}_{3}$ & + & - & - & - & 0 \\
$\boldsymbol{u}_{3}$ & 0 & - & - & 0 & - \\
$\boldsymbol{u}_{5}$ & + & - & - & - & - \\
$\boldsymbol{u}_{6}$ & 0 & + & - & 0 & + \\
\hline
\end{tabular}

Note:,-+ and 0 mean the agent in the corresponding row disagrees with, agrees with and remains neutral about the issue in the corresponding column, respectively.

Definition 2.1 [20] Let $U$ be the universe of all agents and $V$ be the universe of all issues in a conflict. Then, the CIS of the conflict can be expressed as $(U, V)$.

Definition 2.2 [20] The probabilistic CIS over two universes can be defined as a quadruple $(U, V, F, P)$, where $U=\left\{u_{1}, u_{2}, \cdots, u_{m}\right\}$ is the universe of all agents of a conflict, $V=\left\{a_{1}, a_{2}, \cdots, a_{n}\right\}$ is the universe of all issues of the conflict, $F=\left\{F^{+}, F^{-}\right\}$is two set-valued mappings from $U$ to $V$ $\left(F^{+}, F^{-}: U \rightarrow 2^{V}\left(2^{V}=\left\{X_{1}, X_{2}, \cdots, X_{2}|V|\right\}\right.\right.$ is all subsets of universe $V$ with $2^{V}$ states)), and $P$ is a probability measure defined on the $\sigma$ algebra over $\left\{F^{+}(u) \mid u \in U\right\} \subseteq 2^{V}$ on universe $V$.

Definition 2.3 [20] Let $(U, V, F, P)$ be a probabilistic CIS over two universes. For any subset $X \in 2^{V}, X$ is called the feasible consensus strategy for a conflict. In other words, the optimal strategy is a subset of $V$ which satisfies the preset rule or criterion for all agents with respect to the conflict.
Definition 2.4 [20] Let $(U, V, F, P)$ be a probabilistic CIS over two universes. Then, $F^{+}\left(u_{i}\right)=$ $\left\{a_{j} \mid a_{j}\left(u_{i}\right)=+, a_{j} \in V\right\}, u_{i} \in U \quad$ and $\quad F^{-}\left(u_{i}\right)=$ $\left\{a_{j} \mid a_{j}\left(u_{i}\right)=-, a_{j} \in V\right\}, u_{i} \in U$ are defined as the subsets of issues agreed and disagreed by agent $u_{i}$ over universe $V$, respectively.

Let $(U, V, F, P)$ be a probabilistic CIS over two universes. For any $0 \leq \beta<\alpha \leq 1$ and any feasible consensus strategy $X \in 2^{V}$, the lower and upper approximations of $X$ about $(U, V, F, P)$ with respect to parameters $\alpha$ and $\beta$ for $F=$ $\left\{F^{+}, F^{-}\right\}$can be expressed as $\operatorname{Apr}_{P}^{+}(X)=$ $\left\{u_{i} \in U \mid P\left(X \mid F^{+}\left(u_{i}\right)\right) \geq \alpha\right\}, \overline{\operatorname{Apr}}_{P}^{+}(X)=$ $\left\{u_{i} \in U \mid P\left(X \mid F^{+}\left(u_{i}\right)\right)>\beta\right\} \quad$ and $\left\{u_{i} \in U \mid P\left(X \mid F^{-}\left(u_{i}\right)\right) \geq \alpha\right\}, \overline{\operatorname{Apr}}_{P}^{-}(X)=$ $\left\{u_{i} \in U \mid P\left(X \mid F^{-}\left(u_{i}\right)\right)>\beta\right\}$, respectively.

If $\operatorname{Apr}_{P}^{+}(X) \neq \overline{A p r}_{P}^{+}(X)$ or $\operatorname{Apr}_{P}^{-}(X) \neq \overline{A p r}_{P}^{-}(X)$, then the intervals $\left(\operatorname{Apr}_{P}^{+}(X), \overline{A p r}_{P}^{+}(X)\right)$ and $\left(\operatorname{Apr}_{P}^{-}(X), \overline{A p r}_{P}^{-}(X)\right)$ are the probabilistic RSs of the CIS over two universes, respectively.

\subsection{The FRS-CIS}

Drawing on the above concepts of RST-based conflict analysis, this subsection defines the concepts of FRS-based conflict analysis. The FRS-CIS was discussed as follows:

Let $U=\left\{u_{1}, u_{2}, \cdots, u_{m}\right\}$ be the universe of all investors and $V=\left\{a_{1}, a_{2}, \cdots, a_{n}\right\}$ be the universe of all projects in a conflict [17]. Then, the likelihood for each investor to choose each project can be summed up as a CIS (Table 2).

Table 2. The CIS for conflict between investors on projects

\begin{tabular}{ccccccc}
\hline $\boldsymbol{U} / \boldsymbol{V}$ & $\boldsymbol{a}_{\boldsymbol{1}}$ & $\boldsymbol{a}_{\mathbf{2}}$ & $\boldsymbol{a}_{3}$ & $\boldsymbol{a}_{4}$ & $\boldsymbol{a}_{5}$ & $\boldsymbol{a}_{\boldsymbol{6}}$ \\
\hline $\boldsymbol{u}_{\boldsymbol{1}}$ & 0.85 & 0.25 & 0.75 & 0.20 & 0 & 0.80 \\
$\boldsymbol{u}_{\mathbf{2}}$ & 0.55 & 0.75 & 0.20 & 0.75 & 0.85 & 0.55 \\
$\boldsymbol{u}_{\boldsymbol{3}}$ & 0.45 & 0.15 & 0.90 & 0.20 & 0.25 & 0.60 \\
$\boldsymbol{u}_{4}$ & 0.50 & 0.20 & 0.85 & 0.75 & 0.90 & 0.60 \\
$\boldsymbol{u}_{5}$ & 0.20 & 0.90 & 0.30 & 0.80 & 0.75 & 0.30 \\
$\boldsymbol{u}_{\boldsymbol{6}}$ & 0.55 & 0.45 & 0.30 & 0.75 & 0.90 & 0.50 \\
$\boldsymbol{u}_{7}$ & 0.80 & 0.70 & 0.90 & 0.40 & 0 & 0.75 \\
$\boldsymbol{u}_{\boldsymbol{8}}$ & 0.30 & 0.70 & 1 & 0.45 & 0 & 0.75 \\
$\boldsymbol{u}_{9}$ & 0.90 & 0.25 & 0.20 & 0.30 & 1 & 0.40 \\
$\boldsymbol{u}_{10}$ & 0.80 & 0.40 & 0.90 & 0 & 0.80 & 0.80 \\
\hline
\end{tabular}

Note: 0,1 and $(0,1)$ mean the investor corresponding row disagrees with, agrees with and remains neutral about the project in the corresponding column, respectively; the value in $(0,1)$ is positively correlated with the likelihood for the investor to choose the project.

Obviously, the traditional CIS cannot describe the conflict between investors on projects. Therefore, it is necessary to provide the FRS-CIS over two universes.

Definition 2.5 Let $U$ be the universe of all investors, $V$ be the universe of all projects, and $F$ be the fuzzy relation between $U$ and $V$. Then, the FRS-CIS can be expressed as $(U, V, F)$.

Definition 2.6 The probabilistic FRS-CIS over two universes can be defined as $(U, V, F, f, P)$, where $U=$ $\left\{u_{1}, u_{2}, \cdots, u_{m}\right\}$ is the universe of all investors of an FRS conflict, $V=\left\{a_{1}, a_{2}, \cdots, a_{n}\right\}$ is the universe of all projects of the FRS conflict, $f=\left\{f^{+}, f^{-}\right\}$is two set-valued mappings from $U$ to $V\left(f^{+}, f^{-}: U \rightarrow 2^{V}\left(2^{V}=\left\{Y_{1}, Y_{2}, \cdots, Y_{2}|V|\right\}\right.\right.$ is all 
subsets of universe $V$ with $2^{V}$ states)), and $P$ is a probability measure.

For any set of projects $Y \in 2^{V}$ in the FRS conflict $(U, V, F, f, P)$, the lower and upper approximations for $f=$ $\left\{f^{+}, f^{-}\right\}$can be respectively defined as:

$$
\begin{aligned}
& \quad \operatorname{Apr}_{f}^{+}(Y)=\left\{u_{i} \in U \mid f^{+}\left(u_{i}\right) \subseteq Y\right\}, \overline{\operatorname{Apr}}_{f}^{+}(Y)= \\
& \left\{u_{i} \in U \mid f^{+}\left(u_{i}\right) \cap Y \neq \emptyset\right\}, \\
& \quad \frac{\operatorname{Apr}_{f}^{-}}{}(Y)=\left\{u_{i} \in U \mid f^{-}\left(u_{i}\right) \subseteq Y\right\}, \overline{\operatorname{Apr}}_{f}^{-}(Y)= \\
& \left\{u_{i} \in U \mid f^{-}\left(u_{i}\right) \cap Y \neq \emptyset\right\} .
\end{aligned}
$$

Furthermore, it is easy to find that the following relations are valid:

$$
\begin{aligned}
& \overline{A p r}_{f}^{+}(Y) \subseteq \overline{A p r}_{f}^{+}(Y) ; \\
& \overline{A p r}_{f}^{-}(Y) \subseteq \overline{A p r}_{f}^{-}(Y) ; \\
& \overline{A p r}_{f}^{+}(Y) \cap \overline{A p r}_{f}^{-}(Y)=\emptyset ; \\
& \overline{A p r}_{f}^{-}(Y) \cap=\emptyset .
\end{aligned}
$$

Proposition 2.1 Let $(U, V, F, f, P)$ be a probabilistic FRSCIS over two universes. For any $Y \in 2^{V}$, the following properties are valid:

(1) $\operatorname{Apr}_{f}^{+}(\varnothing)=\overline{A p r}_{f}^{+}(\varnothing)=\emptyset, \operatorname{Apr}_{f}^{-}(\varnothing)=\overline{A p r}_{f}^{-}(\varnothing)=\emptyset$

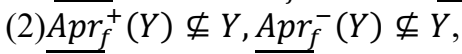

(3) $\overline{A p r}_{f}^{+}(Y) \nsupseteq Y, \overline{A p r}_{f}^{-}(Y) \nsupseteq Y$,

(4) $\operatorname{Apr}_{f}^{+}(V-Y)=U-\overline{A p r}_{f}^{+}(Y), \operatorname{Apr}_{f}^{-}(V-Y)=U-$ $\overline{\operatorname{Apr}}_{f}^{-}(Y)$.

Proof 2.1 Since (1)-(3) are obviously valid, the following is the proof of (4):

Let $Y \in 2^{V}$,

$\operatorname{Apr}_{f}^{+}(V-Y)=\left\{u_{i} \in U \mid f^{+}\left(u_{i}\right) \subseteq U-Y\right\}=$

$\left\{u_{i} \in U \mid f^{+}\left(u_{i}\right) \nsubseteq Y\right\}=\left\{u_{i} \in U \mid f^{+}\left(u_{i}\right) \cap Y=\emptyset\right\}=U-$

$\left\{u_{i} \in U \mid f^{+}\left(u_{i}\right) \cap Y \neq \emptyset\right\}=U-\overline{A p r}_{f}^{+}(Y)$.

Then, $\operatorname{Apr}_{f}^{-}(V-Y)=U-\overline{A p r}_{f}^{-}(Y)$ can be proved in a similar manner.

Definition 2.7 Let $(U, V, F, f, P)$ be a probabilistic FRSCIS over two universes. For any subset $Y \in 2^{V}, Y$ is called the feasible consensus strategy for an FRS conflict. In other words, the optimal strategy is a subset of $V$ which satisfies the preset rule or criterion for all investors with respect to the FRS conflict.

According to Zhao et al. [17], $(U, V, F, f, P)$ is a generalized fuzzy probabilistic approximation space, where $U$ $\left(U=\left\{u_{1}, u_{2}, \cdots, u_{m}\right\}\right)$ and $V$ are two universes of discourse, $R$ is a fuzzy relation from $U$ to $V, P\left(X \mid[x]_{R}\right)=\frac{\sum u_{i} \in X R\left(u_{i}\right) p_{i}}{\sum u_{i} \in U R\left(u_{i}\right) p_{i}}$ and

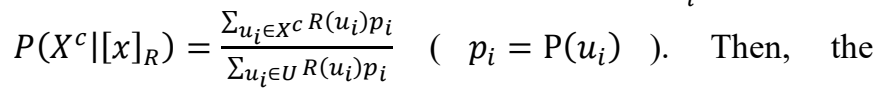
probability measure can be defined as follows based on FRSCIS over two universes:

Definition 2.8 Let $(U, V, F, f, P)$ be a probabilistic FRSCIS over two universes, where $U=\left\{u_{1}, u_{2}, \cdots, u_{m}\right\}$ and $V=$ $\left\{a_{1}, a_{2}, \cdots, a_{n}\right\}$ are two finite sets, $Y \in 2^{V}$ be the feasible consensus strategy, $f^{+}, f^{-}: U \rightarrow 2^{V}$ and $p_{i}=\mathrm{P}\left(a_{i}\right)$. Then, the probability measure can be computed by:

$$
P\left(f^{+}\left(u_{i}\right) \mid Y\right)=\frac{\sum_{a_{j} \in f^{+}\left(u_{i}\right)} a_{j}\left(u_{i}\right) p_{j}}{\sum_{a_{j} \in Y} a_{j}\left(u_{i}\right) p_{j}}
$$

$$
P\left(f^{-}\left(u_{i}\right) \mid Y\right)=\frac{\sum_{a_{j} \in f^{-}\left(u_{i}\right)} a_{j}\left(u_{i}\right) p_{j}}{\sum_{a_{j} \in Y} a_{j}\left(u_{i}\right) p_{j}}
$$

The above definition shows that $P\left(f^{+}\left(u_{i}\right) \mid Y\right)=0$ if $\sum_{a_{j} \in f^{+}\left(u_{i}\right)} a_{j}\left(u_{i}\right) p_{j}=0 \quad, \quad$ and $P\left(f^{+}\left(u_{i}\right) \mid Y\right)=1 \quad$ if $\sum_{a_{j} \in f^{+}\left(u_{i}\right)} a_{j}\left(u_{i}\right) p_{j}=\sum_{a_{j} \in Y} a_{j}\left(u_{i}\right) p_{j}$.

The same conclusion can be drawn for $P\left(f^{-}\left(u_{i}\right) \mid Y\right)$.

Remark For a given FRS conflict, there might be $f^{+}\left(u_{i}\right)=$ $\varnothing$ and $f^{-}\left(u_{i}\right)=\varnothing$. Thus, $P\left(f^{+}\left(u_{i}\right) \mid Y\right)=0$ and $P\left(f^{-}\left(u_{i}\right) \mid Y\right)=1$ are defined separately.

Proposition 2.2 Let $(U, V, F, f, P)$ be a probabilistic FRSCIS over two universes. For $Y \in 2^{V}$, we have:

(1) $P\left(f^{+}\left(u_{i}\right) \mid Y\right)+P\left(\left(f^{+}\left(u_{i}\right)\right)^{c} \mid Y\right)=1, P\left(f^{-}\left(u_{i}\right) \mid Y\right)+$ $P\left(\left(f^{-}\left(u_{i}\right)\right)^{c} \mid Y\right)=1$,

(2) $P\left(f^{+}\left(u_{i}\right) \mid Y\right)+P\left(f^{-}\left(u_{i}\right) \mid Y\right)=1$.

The above properties are obviously valid.

Definition 2.9 Let $(U, V, F, f, P)$ be a probabilistic FRSCIS over two universes. Then, the subsets of projects agreed and disagreed by investor $u_{i}$ over universe $V$ can be respectively expressed as:

$$
\begin{aligned}
& f^{+}\left(u_{i}\right)=\left\{a_{j} \mid a_{j}\left(u_{i}\right)=1, a_{j} \in V\right\}, u_{i} \in U \\
& f^{-}\left(u_{i}\right)=\left\{a_{j} \mid a_{j}\left(u_{i}\right)=0, a_{j} \in V\right\}, u_{i} \in U
\end{aligned}
$$

For any $0 \leq \beta<\alpha \leq 1$, the lower and upper approximations of the feasible consensus strategy $Y$ about $(U, V, F, f, P)$ with respect to parameters $\alpha$ and $\beta$ can be respectively expressed as:

$$
\begin{aligned}
& \operatorname{Apr}_{P}^{+}(Y)=\left\{u_{i} \in U \mid P\left(f^{+}\left(u_{i}\right) \mid Y\right) \geq \alpha\right\}, \overline{\operatorname{Apr}}_{P}^{+}(Y)= \\
& \left\{u_{i} \in U \mid P\left(f^{+}\left(u_{i}\right) \mid Y\right)>\beta\right\}, \\
& \quad \frac{\operatorname{Apr}_{P}^{-}(Y)=\left\{u_{i} \in U \mid P\left(f^{-}\left(u_{i}\right) \mid Y\right) \geq \alpha\right\}, \overline{\operatorname{Apr}}_{P}^{-}(Y)=}{\left\{u_{i} \in U \mid P\left(f^{-}\left(u_{i}\right) \mid Y\right)>\beta\right\} .} \\
& \quad \text { If } \underline{\operatorname{Apr}}+(Y) \neq \overline{\operatorname{Apr}}_{P}^{+}(Y) \text { or } \operatorname{Apr}_{P}^{-}(Y) \neq \overline{\operatorname{Apr}}_{P}^{-}(Y) \text {, then the } \\
& \text { interval }\left(\underline{A p r}_{P}^{+}(Y), \overline{\operatorname{Apr}}_{P}^{+}(Y)\right) \text { or }\left(\operatorname{Apr}_{P}^{-}(Y), \overline{\operatorname{Apr}}_{P}^{-}(Y)\right) \text { is the }
\end{aligned}
$$
$(0,1)$-probabilistic FRS of the FRS-CIS over two universes.

Example 1 Let $U=\left\{u_{1}, u_{2}, \cdots, u_{10}\right\}$ be the set of sufferers and $V=\left\{a_{1}, a_{2}, \cdots, a_{5}\right\}$ be the set of symptoms [25]. If the probability distribution on $V$ is $\{0.2,0.2,0.1,0.2,0.3\}$, then the likelihood for each sufferer to have each symptom can be illustrated by the fuzzy CIS in Table 3 .

Table 3. The fuzzy CIS for the conflict between sufferers on symptoms

\begin{tabular}{llllll}
\hline $\boldsymbol{U} / \boldsymbol{V}$ & $\boldsymbol{a}_{1}$ & $\boldsymbol{a}_{\mathbf{2}}$ & $\boldsymbol{a}_{\mathbf{3}}$ & $\boldsymbol{a}_{4}$ & $\boldsymbol{a}_{\mathbf{5}}$ \\
\hline $\boldsymbol{u}_{\boldsymbol{1}}$ & 0.85 & 0.25 & 0.77 & 0.17 & 0 \\
$\boldsymbol{u}_{\mathbf{2}}$ & 0.62 & 0.74 & 0.17 & 0.53 & 0.81 \\
$\boldsymbol{u}_{3}$ & 0.45 & 0.10 & 0.89 & 0.18 & 0.24 \\
$\boldsymbol{u}_{4}$ & 0.47 & 0.17 & 0.83 & 0.74 & 0.91 \\
$\boldsymbol{u}_{5}$ & 0.20 & 0.90 & 0.30 & 0.80 & 0.75 \\
$\boldsymbol{u}_{6}$ & 0.81 & 0.30 & 0.30 & 0.82 & 0.90 \\
$\boldsymbol{u}_{7}$ & 0.82 & 0.70 & 0.87 & 0.40 & 0 \\
$\boldsymbol{u}_{\boldsymbol{8}}$ & 0.31 & 0.73 & 1 & 0.44 & 0 \\
$\boldsymbol{u}_{9}$ & 0.91 & 0.25 & 0.20 & 0.30 & 1 \\
$\boldsymbol{u}_{10}$ & 0.82 & 0.40 & 0.90 & 0 & 0.78 \\
\hline
\end{tabular}


The following can be derived from the set-valued mappings $f=\left\{f^{+}, f^{-}\right\}$from $U$ to $V\left(f^{+}\left(u_{i}\right)=\left\{a_{j} \mid a_{j}\left(u_{i}\right)=1, a_{j} \in V\right\}\right.$, $u_{i} \in U$ and $\left.f^{-}\left(u_{i}\right)=\left\{a_{j} \mid a_{j}\left(u_{i}\right)=0, a_{j} \in V\right\}, u_{i} \in U\right)$ :

$$
f^{+}\left(u_{1}\right)=\emptyset, f^{+}\left(u_{2}\right)=\emptyset, f^{+}\left(u_{3}\right)=\emptyset, f^{+}\left(u_{4}\right)=
$$

$\emptyset, f^{+}\left(u_{5}\right)=\emptyset$,

$f^{+}\left(u_{6}\right)=\emptyset, f^{+}\left(u_{7}\right)=\emptyset, f^{+}\left(u_{8}\right)=\left\{\left(a_{3}, 1\right)\right\}, f^{+}\left(u_{9}\right)=$

$\left\{\left(a_{5}, 1\right)\right\}, f^{+}\left(u_{10}\right)=\emptyset$.

$f^{-}\left(u_{1}\right)=\left\{\left(a_{5}, 0\right)\right\}, f^{-}\left(u_{2}\right)=\emptyset, f^{-}\left(u_{3}\right)=\emptyset, f^{-}\left(u_{4}\right)=$

$\emptyset, f^{-}\left(u_{5}\right)=\emptyset$,

$f^{-}\left(u_{6}\right)=\emptyset, f^{-}\left(u_{7}\right)=\left\{\left(a_{5}, 0\right)\right\}, f^{-}\left(u_{8}\right)=$

$\left\{\left(a_{5}, 0\right)\right\}, f^{-}\left(u_{9}\right)=\emptyset, f^{-}\left(u_{10}\right)=\left\{\left(a_{4}, 0\right)\right\}$.

Let $Y=V$ be the feasible consensus strategy, then the probability measure can be calculated for each $u_{i} \in U$ by (1) and (2):

$P\left(f^{+}\left(u_{1}\right) \mid Y\right)=0, P\left(f^{+}\left(u_{2}\right) \mid Y\right)=0, P\left(f^{+}\left(u_{3}\right) \mid Y\right)=$

$0, P\left(f^{+}\left(u_{4}\right) \mid Y\right)=0$,

$P\left(f^{+}\left(u_{5}\right) \mid Y\right)=0, P\left(f^{+}\left(u_{6}\right) \mid Y\right)=0, P\left(f^{+}\left(u_{7}\right) \mid Y\right)=$

$0, P\left(f^{+}\left(u_{8}\right) \mid Y\right)=\frac{0.1 \times 1}{0.396}=0.2525$,

$P\left(f^{+}\left(u_{9}\right) \mid Y\right)=\frac{0.3 \times 1}{0.612}=0.4902, P\left(f^{+}\left(u_{10}\right) \mid Y\right)=0$.

$P\left(f^{-}\left(u_{1}\right) \mid Y\right)=0, P\left(f^{-}\left(u_{2}\right) \mid Y\right)=1, P\left(f^{-}\left(u_{3}\right) \mid Y\right)=$

1, $P\left(f^{-}\left(u_{4}\right) \mid Y\right)=1$,

$P\left(f^{-}\left(u_{5}\right) \mid Y\right)=1, P\left(f^{-}\left(u_{6}\right) \mid Y\right)=1, P\left(f^{-}\left(u_{7}\right) \mid Y\right)=$

$0, P\left(f^{-}\left(u_{8}\right) \mid Y\right)=0$,

$P\left(f^{-}\left(u_{9}\right) \mid Y\right)=1, P\left(f^{-}\left(u_{10}\right) \mid Y\right)=0$.

The above $f^{+}\left(u_{i}\right)$ and $f^{-}\left(u_{i}\right)$ are too strict and lack tolerance. Considering the 0.5-probabilistic RS [26], the setvalued mappings $f^{+}, f^{-}: U \rightarrow 2^{V}$ can be respectively defined as:

Definition 2.10 Let $(U, V, F, f, P)$ be a probabilistic FRSCIS over two universes. Then, the subsets of projects agreed and disagreed by investor $u_{i}$ over universe $V$ can be respectively expressed as:

$$
\begin{aligned}
& f^{+}\left(u_{i}\right)=\left\{a_{j} \mid a_{j}\left(u_{i}\right) \geq 0.5, a_{j} \in V\right\}, u_{i} \in U \\
& f^{-}\left(u_{i}\right)=\left\{a_{j} \mid a_{j}\left(u_{i}\right)<0.5, a_{j} \in V\right\}, u_{i} \in U
\end{aligned}
$$

The lower and upper approximations of the feasible consensus strategy $Y$ about $(U, V, F, f, P)$ with respect to parameters $\alpha$ and $\beta$ can be respectively expressed as:

$$
\begin{aligned}
& \operatorname{Apr}_{P}^{+}(Y)=\left\{u_{i} \in U \mid P\left(f^{+}\left(u_{i}\right) \mid Y\right) \geq \alpha\right\}, \overline{\operatorname{Apr}}_{P}^{+}(Y)= \\
& \left\{u_{i} \in U \mid P\left(f^{+}\left(u_{i}\right) \mid Y\right)>\beta\right\} \quad, \quad \operatorname{Apr}_{P}^{-}(Y)= \\
& \left\{u_{i} \in U \mid P\left(f^{-}\left(u_{i}\right) \mid Y\right) \geq \alpha\right\}, \overline{\operatorname{Apr}}_{P}^{-}(Y)= \\
& \left\{u_{i} \in U \mid P\left(f^{-}\left(u_{i}\right) \mid Y\right)>\beta\right\} \text {. }
\end{aligned}
$$
0.5 -probabilistic FRS of the FRS-CIS over two universes.

Example 2 (Continued from Example 1) The following can be derived from the set-valued mappings $f=\left\{f^{+}, f^{-}\right\}$from $U$ to $V \quad\left(f^{+}\left(u_{i}\right)=\left\{a_{j} \mid a_{j}\left(u_{i}\right) \geq 0.5, a_{j} \in V\right\}, u_{i} \in U\right.$ and $\left.f^{-}\left(u_{i}\right)=\left\{a_{j} \mid a_{j}\left(u_{i}\right)<0.5, a_{j} \in V\right\}, u_{i} \in U\right)$ :

$f^{+}\left(u_{1}\right)=\left\{\left(a_{1}, 0.85\right),\left(a_{3}, 0.77\right)\right\}$,

$f^{+}\left(u_{2}\right)=$

$\left\{\left(a_{1}, 0.62\right),\left(a_{2}, 0.74\right),\left(a_{4}, 0.53\right),\left(a_{5}, 0.81\right)\right\}, f^{+}\left(u_{3}\right)=$

$\left\{\left(a_{3}, 0.89\right)\right\}$,

$f^{+}\left(u_{4}\right)=\left\{\left(a_{3}, 0.83\right),\left(a_{4}, 0.74\right),\left(a_{5}, 0.91\right)\right\}$

$f^{+}\left(u_{5}\right)=\left\{\left(a_{2}, 0.90\right),\left(a_{4}, 0.80\right),\left(a_{5}, 0.75\right)\right\}$,

$f^{+}\left(u_{6}\right)=\left\{\left(a_{1}, 0.81\right),\left(a_{4}, 0.82\right),\left(a_{5}, 0.90\right)\right\}$, $f^{+}\left(u_{7}\right)=\left\{\left(a_{1}, 0.82\right),\left(a_{2}, 0.70\right),\left(a_{3}, 0.87\right)\right\}, f^{+}\left(u_{8}\right)=$

$\left\{\left(a_{2}, 0.73\right),\left(a_{3}, 1\right)\right\}$,

$f^{+}\left(u_{9}\right)=\left\{\left(a_{1}, 0.91\right),\left(a_{5}, 1\right)\right\}, f^{+}\left(u_{10}\right)=$

$\left\{\left(a_{1}, 0.82\right),\left(a_{3}, 0.90\right),\left(a_{5}, 0.78\right)\right\}$.

$f^{-}\left(u_{1}\right)=\left\{\left(a_{2}, 0.25\right),\left(a_{4}, 0.17\right),\left(a_{5}, 0\right)\right\}, f^{-}\left(u_{2}\right)=$

$\left\{\left(a_{3}, 0.17\right)\right\}$,

$f^{-}\left(u_{3}\right)=\left\{\left(a_{1}, 0.45\right),\left(a_{2}, 0.10\right),\left(a_{4}, 0.18\right),\left(a_{5}, 0.24\right)\right\}$,

$f^{-}\left(u_{4}\right)=\left\{\left(a_{1}, 0.47\right),\left(a_{2}, 0.17\right)\right\}, f^{-}\left(u_{5}\right)=$

$\left\{\left(a_{1}, 0.20\right),\left(a_{3}, 0.30\right)\right\}$,

$f^{-}\left(u_{6}\right)=\left\{\left(a_{2}, 0.30\right),\left(a_{3}, 0.30\right)\right\}, f^{-}\left(u_{7}\right)=$

$\left\{\left(a_{4}, 0.40\right),\left(a_{5}, 0\right)\right\}$,

$f^{-}\left(u_{8}\right)=\left\{\left(a_{1}, 0.31\right),\left(a_{2}, 0.44\right),\left(a_{5}, 0\right)\right\}, f^{-}\left(u_{9}\right)=$

$\left\{\left(a_{2}, 0.25\right),\left(a_{3}, 0.20\right),\left(a_{4}, 0.30\right)\right\}$,

$f^{-}\left(u_{10}\right)=\left\{\left(a_{2}, 0.40\right),\left(a_{4}, 0\right)\right\}$.

Let $Y=V$ be the feasible consensus strategy, then the probability measure can be calculated for each $u_{i} \in U$ by (1) and (2):

$P\left(f^{+}\left(u_{1}\right) \mid Y\right)=0.7462, P\left(f^{+}\left(u_{2}\right) \mid Y\right)=$

$0.9734, P\left(f^{+}\left(u_{3}\right) \mid Y\right)=0.2899$

$P\left(f^{+}\left(u_{4}\right) \mid Y\right)=0.7975, P\left(f^{+}\left(u_{5}\right) \mid Y\right)=$

0.8898, $P\left(f^{+}\left(u_{6}\right) \mid Y\right)=0.8688$

$P\left(f^{+}\left(u_{7}\right) \mid Y\right)=0.8301, P\left(f^{+}\left(u_{8}\right) \mid Y\right)=$

$0.6212, P\left(f^{+}\left(u_{9}\right) \mid Y\right)=0.7876$,

$P\left(f^{+}\left(u_{10}\right) \mid Y\right)=0.8592$.

$P\left(f^{-}\left(u_{1}\right) \mid Y\right)=0.2538, P\left(f^{-}\left(u_{2}\right) \mid Y\right)=$

0.0266, $P\left(f^{-}\left(u_{3}\right) \mid Y\right)=0.7101$,

$P\left(f^{-}\left(u_{4}\right) \mid Y\right)=0.2025, P\left(f^{-}\left(u_{5}\right) \mid Y\right)=$

$0.1102, P\left(f^{-}\left(u_{6}\right) \mid Y\right)=0.1312$,

$P\left(f^{-}\left(u_{7}\right) \mid Y\right)=0.1699, P\left(f^{-}\left(u_{8}\right) \mid Y\right)=$

0.3788, $P\left(f^{-}\left(u_{9}\right) \mid Y\right)=0.2124$,

$P\left(f^{-}\left(u_{10}\right) \mid Y\right)=0.1408$.

\section{THREE-WAY DECISION THEORETIC FRS UNDER FRS-CIS OVER TWO UNIVERSES}

This section introduces the three-way decision theoretic RS under the CIS over two universes, and then sets up the threeway decision models of $(0,1)$-probabilistic FRS and 0.5probabilistic FRS.

\subsection{The three-way decision theoretic RS under the CIS over two universes}

The decision rules for probabilistic RS of the CIS over two universes were presented, according to the decision-theoretic framework for probabilistic RS proposed by Yao et al. [26, 27] based on the Bayesian decision procedure.

Suppose $U$ and $V$ are the agent set and issue set of a conflict, respectively, and $X \in 2^{V}$ is a feasible consensus strategy of the conflict. Let $A=\left\{d_{1}, d_{2}, d_{3}\right\}$ be the three decisions of agent $u_{i} \in U$ over the feasible consensus strategy $X$ : agreement, disagreement and neutrality. In the case of $X$, the cost or risk to agree, disagree or stay neutral can be respectively denoted as $\lambda_{11}=\lambda\left(d_{1} \mid X\right), \lambda_{21}=\lambda\left(d_{2} \mid X\right)$ and $\lambda_{31}=\lambda\left(d_{3} \mid X\right)$; in the case of $X^{c}$, the cost or risk to agree, disagree or stay neutral can be respectively denoted as $\lambda_{12}=$ $\lambda\left(d_{1} \mid X^{c}\right), \lambda_{22}=\lambda\left(d_{2} \mid X^{c}\right)$ and $\lambda_{32}=\lambda\left(d_{3} \mid X^{c}\right)$.

Based on the rough set under the CIS over two universes, the expected risk $R^{\diamond}\left(d_{t} \mid u_{i}\right)(\diamond \in\{+,-\}, t=1,2,3)$ of any agent $u_{i} \in U$ to agree with, disagree with or stay neutral to the feasible consensus strategy $X$ can be expressed as: 


$$
\begin{gathered}
R^{+}\left(d_{1} \mid u_{i}\right)=R\left(d_{1} \mid F^{+}\left(u_{i}\right)\right)= \\
\lambda\left(d_{1} \mid X\right) P\left(X \mid F^{+}\left(u_{i}\right)\right)+\lambda\left(d_{1} \mid X^{c}\right) P\left(X^{c} \mid F^{+}\left(u_{i}\right)\right), \\
R^{+}\left(d_{2} \mid u_{i}\right)=R\left(d_{2} \mid F^{+}\left(u_{i}\right)\right)= \\
\lambda\left(d_{2} \mid X\right) P\left(X \mid F^{+}\left(u_{i}\right)\right)+\lambda\left(d_{2} \mid X^{c}\right) P\left(X^{c} \mid F^{+}\left(u_{i}\right)\right), \\
R^{+}\left(d_{3} \mid u_{i}\right)=R\left(d_{3} \mid F^{+}\left(u_{i}\right)\right) \\
=\lambda\left(d_{3} \mid X\right) P\left(X \mid F^{+}\left(u_{i}\right)\right) \\
+\lambda\left(d_{3} \mid X^{c}\right) P\left(X^{c} \mid F^{+}\left(u_{i}\right)\right)
\end{gathered}
$$

and

$$
\begin{gathered}
R^{-}\left(d_{1} \mid u_{i}\right)=R\left(d_{1} \mid F^{-}\left(u_{i}\right)\right)= \\
\lambda\left(d_{1} \mid X\right) P\left(X \mid F^{-}\left(u_{i}\right)\right)+\lambda\left(d_{1} \mid X^{c}\right) P\left(X^{c} \mid F^{-}\left(u_{i}\right)\right) \\
R^{-}\left(d_{2} \mid u_{i}\right)=R\left(d_{2} \mid F^{-}\left(u_{i}\right)\right) \\
=\lambda\left(d_{2} \mid X\right) P\left(X \mid F^{-}\left(u_{i}\right)\right) \\
+\lambda\left(d_{2} \mid X^{c}\right) P\left(X^{c} \mid F^{-}\left(u_{i}\right)\right) \\
R^{-}\left(d_{3} \mid u_{i}\right)=R\left(d_{3} \mid F^{-}\left(u_{i}\right)\right) \\
=\lambda\left(d_{3} \mid X\right) P\left(X \mid F^{-}\left(u_{i}\right)\right) \\
+\lambda\left(d_{3} \mid X^{c}\right) P\left(X^{c} \mid F^{-}\left(u_{i}\right)\right)
\end{gathered}
$$

Here, the relation for $\lambda_{i j}(i=1,2,3, j=1,2)$ is assumed as follows:

$$
\lambda_{11} \leq \lambda_{31}<\lambda_{21}, \lambda_{12}>\lambda_{32} \geq \lambda_{22}
$$

For any agent $u_{i} \in U$, the minimum risk decision rules for $F^{+}\left(u_{i}\right)=\left\{a_{j} \mid a_{j}\left(u_{i}\right)=+, a_{j} \in V\right\}, u_{i} \in U$ based on the RS under the CIS over two universes can be derived from the Bayesian decision procedure over two universes[28, 29]:

(P1) Making the decision $\operatorname{Pos}_{P}^{+}(X)$ if $R\left(d_{1} \mid F^{+}\left(u_{i}\right)\right)<$ $R\left(d_{2} \mid F^{+}\left(u_{i}\right)\right)$ and $R\left(d_{1} \mid F^{+}\left(u_{i}\right)\right)<R\left(d_{3} \mid F^{+}\left(u_{i}\right)\right)$;

(N1) Making the $\operatorname{decision} \operatorname{Neg}_{P}^{+}(X)$ if $R\left(d_{2} \mid F^{+}\left(u_{i}\right)\right)<$ $R\left(d_{1} \mid F^{+}\left(u_{i}\right)\right)$ and $R\left(d_{2} \mid F^{+}\left(u_{i}\right)\right)<R\left(d_{3} \mid F^{+}\left(u_{i}\right)\right)$;

(B1) Making the decision $\mathrm{Bn}_{P}^{+}(X)$ if $R\left(d_{3} \mid F^{+}\left(u_{i}\right)\right)<$ $R\left(d_{1} \mid F^{+}\left(u_{i}\right)\right)$ and $R\left(d_{3} \mid F^{+}\left(u_{i}\right)\right)<R\left(d_{2} \mid F^{+}\left(u_{i}\right)\right)$;

Based on the RS under the CIS over two universes, the minimum risk decision rules $(\mathrm{P} 1),(\mathrm{N} 1)$ and $(\mathrm{B} 1)$ can be written as follows for any agent $u_{i} \in U$ :

(P2) Making the decision $\operatorname{Pos}_{P}^{+}(X)$ if $P\left(X \mid F^{+}\left(u_{i}\right)\right) \geq \alpha$ and $P\left(X \mid F^{+}\left(u_{i}\right)\right) \geq \gamma$;

(N2) Making the decision $\operatorname{Neg}_{P}^{+}(X)$ if $P\left(X \mid F^{+}\left(u_{i}\right)\right) \leq \beta$ and $P\left(X \mid F^{+}\left(u_{i}\right)\right)<\gamma$;

(B2) Making the decision $\operatorname{Bn}_{P}^{+}(X)$ if $P\left(X \mid F^{+}\left(u_{i}\right)\right)<\alpha$ and $P\left(X \mid F^{+}\left(u_{i}\right)\right)>\beta$.

where,

$$
\begin{aligned}
& \alpha=\frac{\lambda_{12}-\lambda_{32}}{\left(\lambda_{12}-\lambda_{32}\right)+\left(\lambda_{31}-\lambda_{11}\right)} \\
& \beta=\frac{\lambda_{32}-\lambda_{22}}{\left(\lambda_{32}-\lambda_{22}\right)+\left(\lambda_{21}-\lambda_{31}\right)} \\
& \gamma=\frac{\lambda_{12}-\lambda_{22}}{\left(\lambda_{12}-\lambda_{22}\right)+\left(\lambda_{21}-\lambda_{11}\right)}
\end{aligned}
$$

By the principle of three-way decision [4, 28], the following equations can be derived from the RS under the CIS:

(P3) Agreement (Decision positive region):

$\operatorname{Pos}_{P}^{+}(X)=\underline{A p r_{P}^{+}}(X)=\left\{u_{i} \in U \mid P\left(X \mid F^{+}\left(u_{i}\right)\right) \geq \alpha\right\}$,

(B3) Neutrality (Decision boundary region):

$\mathrm{Bn}_{P}^{+}(X)=\left\{u_{i} \in U \mid \beta<P\left(X \mid F^{+}\left(u_{i}\right)\right)<\alpha\right\}$,

(N3) Disagreement (Decision negative region):

$\operatorname{Neg}_{P}^{+}(X)=\left\{u_{i} \in U \mid P\left(X \mid F^{+}\left(u_{i}\right)\right) \leq \beta\right\}$.

Based on the RS under the CIS, the following equations can be derived for $R^{-}\left(d_{1} \mid u_{i}\right), R^{-}\left(d_{2} \mid u_{i}\right)$ and $R^{-}\left(d_{3} \mid u_{i}\right)$ :

(P3') Agreement (Decision positive region):

$\operatorname{Pos}_{P}^{-}(X)=\underline{\operatorname{Apr}_{P}^{-}}(X)=\left\{u_{i} \in U \mid P\left(X \mid F^{-}\left(u_{i}\right)\right) \geq \alpha\right\}$,

(B3') Neutrality (Decision boundary region):

$\operatorname{Bn}_{P}^{-}(X)=\left\{u_{i} \in U \mid \beta<P\left(X \mid F^{-}\left(u_{i}\right)\right)<\alpha\right\}$,

(N3') Disagreement (Decision negative region):

$\operatorname{Neg}_{P}^{-}(X)=\left\{u_{i} \in U \mid P\left(X \mid F^{-}\left(u_{i}\right)\right) \leq \beta\right\}$.

Both the set of agreed issues $F^{+}\left(u_{i}\right)$ and the set of disagreed issues $F^{-}\left(u_{i}\right)$ contain decision rules in the CIS over two universes. Therefore, the decision rules in the two set-valued mappings should be considered. For $0 \leq \beta<\alpha \leq 1$, any agent $u_{i} \in U$ and any feasible consensus strategy $X \in 2^{V}$, the following decision rules are available for the RS under the CIS:

(P4) If $P\left(X \mid F^{+}\left(u_{i}\right)\right) \geq \alpha$ and $P\left(X \mid F^{-}\left(u_{i}\right)\right) \leq \beta$, then agent $u_{i}$ agrees with the feasible consensus strategy $X$;

(N4) If $P\left(X \mid F^{+}\left(u_{i}\right)\right) \leq \beta$ and $P\left(X \mid F^{-}\left(u_{i}\right)\right) \geq \alpha$, then agent $u_{i}$ disagrees with the feasible consensus strategy $X$;

(B4) If $\beta<P\left(X \mid F^{+}\left(u_{i}\right)\right)<\alpha$ and $\beta<P\left(X \mid F^{-}\left(u_{i}\right)\right)<\alpha$, then agent $u_{i}$ remains neutral to the feasible consensus strategy $X$.

\subsection{Three-way decision model of (0,1)-probabilistic FRS under FRS-CIS over two universes}

This sub-section discusses the principle and framework of three-way decision model of $(0,1)$-probabilistic FRS in the FRS-CIS.

Suppose $U$ and $V$ are the investor set and project set of an FRS conflict, respectively, and $Y \in 2^{V}$ is a feasible consensus strategy of the conflict. Let $A=\left\{d_{1}, d_{2}, d_{3}\right\}$ be the three decisions of agent $u_{i} \in U$ over the feasible consensus strategy $Y$ : agreement, disagreement and neutrality. In the case of $f^{+}$, the cost or risk to agree, disagree or stay neutral can be respectively denoted as $\lambda_{11}=\lambda\left(d_{1} \mid f^{+}\right), \lambda_{21}=\lambda\left(d_{2} \mid f^{+}\right)$and $\lambda_{31}=\lambda\left(d_{3} \mid f^{+}\right)$; in the case of $\left(f^{+}\right)^{c}$, the cost or risk to agree, disagree or stay neutral can be respectively denoted as $\lambda_{12}=$ $\lambda\left(d_{1} \mid\left(f^{+}\right)^{c}\right), \lambda_{22}=\lambda\left(d_{2} \mid\left(f^{+}\right)^{c}\right)$ and $\lambda_{32}=\lambda\left(d_{3} \mid\left(f^{+}\right)^{c}\right)$.

Based on the $(0,1)$-probabilistic FRS under FRS-CIS over two universes, the expected risk $R^{\diamond}\left(d_{t} \mid u_{i}\right)(\diamond \in\{+,-\}, t=$ $1,2,3)$ of any investor $u_{i} \in U$ to agree with, disagree with or stay neutral to the feasible consensus strategy $Y$ can be expressed as:

$$
\begin{aligned}
& R^{+}\left(d_{1} \mid u_{i}\right) \\
& =\lambda\left(d_{1} \mid f^{+}\left(u_{i}\right)\right) P\left(f^{+}\left(u_{i}\right) \mid Y\right) \\
& +\lambda\left(d_{1} \mid\left(f^{+}\left(u_{i}\right)\right)^{c}\right) P\left(\left(f^{+}\left(u_{i}\right)\right)^{c} \mid Y\right) \\
& R^{+}\left(d_{2} \mid u_{i}\right)=\lambda\left(d_{2} \mid f^{+}\left(u_{i}\right)\right) P\left(f^{+}\left(u_{i}\right) \mid Y\right)+ \\
& \quad \lambda\left(d_{2} \mid\left(f^{+}\left(u_{i}\right)\right)^{c}\right) P\left(\left(f^{+}\left(u_{i}\right)\right)^{c} \mid Y\right),
\end{aligned}
$$

and satisfies $0 \leq \beta<\alpha \leq 1$. 


$$
\begin{aligned}
& R^{+}\left(d_{3} \mid u_{i}\right) \\
& =\lambda\left(d_{3} \mid f^{+}\left(u_{i}\right)\right) P\left(f^{+}\left(u_{i}\right) \mid Y\right) \\
& +\lambda\left(d_{3} \mid\left(f^{+}\left(u_{i}\right)\right)^{c}\right) P\left(\left(f^{+}\left(u_{i}\right)\right)^{c} \mid Y\right)
\end{aligned}
$$

and

$$
\begin{aligned}
& R^{-}\left(d_{1} \mid u_{i}\right) \\
& =\lambda\left(d_{1} \mid f^{-}\left(u_{i}\right)\right) P\left(f^{-}\left(u_{i}\right) \mid Y\right) \\
& +\lambda\left(d_{1} \mid\left(f^{-}\left(u_{i}\right)\right)^{c}\right) P\left(\left(f^{-}\left(u_{i}\right)\right)^{c} \mid Y\right) \\
& R^{-}\left(d_{2} \mid u_{i}\right) \\
& =\lambda\left(d_{2} \mid f^{-}\left(u_{i}\right)\right) P\left(f^{-}\left(u_{i}\right) \mid Y\right) \\
& +\lambda\left(d_{2} \mid\left(f^{-}\left(u_{i}\right)\right)^{c}\right) P\left(\left(f^{-}\left(u_{i}\right)\right)^{c} \mid Y\right) \\
& R^{-}\left(d_{3} \mid u_{i}\right) \\
& =\lambda\left(d_{3} \mid f^{-}\left(u_{i}\right)\right) P\left(f^{-}\left(u_{i}\right) \mid Y\right) \\
& +\lambda\left(d_{3} \mid\left(f^{-}\left(u_{i}\right)\right)^{c}\right) P\left(\left(f^{-}\left(u_{i}\right)\right)^{c} \mid Y\right)
\end{aligned}
$$

Here, the relation for $\lambda_{i j}(i=1,2,3, j=1,2)$ is assumed as follows:

$$
\lambda_{11} \leq \lambda_{31}<\lambda_{21}, \lambda_{12}>\lambda_{32} \geq \lambda_{22}
$$

For any investor $u_{i} \in U$, the minimum risk decision rules for $f^{+}\left(u_{i}\right)=\left\{a_{j} \mid a_{j}\left(u_{i}\right)=1, a_{j} \in V\right\}, u_{i} \in U$ based on the $(0,1)$-probabilistic FRS under FRS-CIS over two universes can be derived from the Bayesian decision procedure over two universes [28, 29]:

(P1) Making the decision $\operatorname{Pos}_{P}^{+}(X)$ if $R^{+}\left(d_{1} \mid u_{i}\right)<$ $R^{+}\left(d_{2} \mid u_{i}\right)$ and $R^{+}\left(d_{1} \mid u_{i}\right)<R^{+}\left(d_{3} \mid u_{i}\right)$;

(N1) Making the decision $\operatorname{Neg}_{P}^{+}(X)$ if $R^{+}\left(d_{2} \mid u_{i}\right)<$ $R^{+}\left(d_{1} \mid u_{i}\right)$ and $R^{+}\left(d_{2} \mid u_{i}\right)<R^{+}\left(d_{3} \mid u_{i}\right)$;

(B1) Making the decision $\operatorname{Bn}_{P}^{+}(X)$ if $R^{+}\left(d_{3} \mid u_{i}\right)<$ $R^{+}\left(d_{1} \mid u_{i}\right)$ and $R^{+}\left(d_{3} \mid u_{i}\right)<R^{+}\left(d_{2} \mid u_{i}\right)$;

Based on the $(0,1)$-probabilistic FRS under FRS-CIS over two universes, the minimum risk decision rules (P1), (N1) and (B1) can be written as follows for any agent $u_{i} \in U$ :

(P2) Making the decision $\operatorname{Pos}_{P}^{+}(X)$ if $P\left(f^{+}\left(u_{i}\right) \mid Y\right) \geq \alpha$ and $P\left(f^{+}\left(u_{i}\right) \mid Y\right) \geq \gamma$;

(N2) Making the decision $\operatorname{Neg}_{P}^{+}(X)$ if $P\left(f^{+}\left(u_{i}\right) \mid Y\right) \leq \beta$ and $P\left(f^{+}\left(u_{i}\right) \mid Y\right)<\gamma$;

(B2) Making the decision $\mathrm{Bn}_{P}^{+}(X)$ if $P\left(f^{+}\left(u_{i}\right) \mid Y\right)<\alpha$ and $P\left(f^{+}\left(u_{i}\right) \mid Y\right)>\beta$.

where,

$$
\begin{aligned}
& \alpha=\frac{\lambda_{12}-\lambda_{32}}{\left(\lambda_{12}-\lambda_{32}\right)+\left(\lambda_{31}-\lambda_{11}\right)} \\
& \beta=\frac{\lambda_{32}-\lambda_{22}}{\left(\lambda_{32}-\lambda_{22}\right)+\left(\lambda_{21}-\lambda_{31}\right)} \\
& \gamma=\frac{\lambda_{12}-\lambda_{22}}{\left(\lambda_{12}-\lambda_{22}\right)+\left(\lambda_{21}-\lambda_{11}\right)}
\end{aligned}
$$

and satisfies the condition of $0 \leq \beta<\alpha \leq 1$.

By the principle of three-way decision [4, 28], the following equations can be derived from the $(0,1)$-probabilistic FRS under FRS-CIS over two universes:

(P3) Agreement (Decision positive region):

$\operatorname{Pos}_{P}^{+}(Y)=\left\{u_{i} \in U \mid P\left(f^{+}\left(u_{i}\right) \mid Y\right) \geq \alpha\right\}$,

(B3) Neutrality (Decision boundary region):

$\operatorname{Bn}_{P}^{+}(Y)=\left\{u_{i} \in U \mid \beta<P\left(f^{+}\left(u_{i}\right) \mid Y\right)<\alpha\right\}$,
(N3) Disagreement (Decision negative region):

$\operatorname{Neg}_{P}^{+}(Y)=\left\{u_{i} \in U \mid P\left(f^{+}\left(u_{i}\right) \mid Y\right) \leq \beta\right\}$.

Based on the $(0,1)$-probabilistic FRS under FRS-CIS over two universes, the following equations can be derived for $R^{-}\left(d_{1} \mid u_{i}\right), R^{-}\left(d_{2} \mid u_{i}\right)$ and $R^{-}\left(d_{3} \mid u_{i}\right)$ :

(P3') Agreement (Decision positive region):

$\operatorname{Pos}_{P}^{-}(Y)=\left\{u_{i} \in U \mid P\left(f^{-}\left(u_{i}\right) \mid Y\right) \geq \alpha\right\}$

(B3') Neutrality (Decision boundary region):

$\operatorname{Bn}_{P}^{-}(Y)=\left\{u_{i} \in U \mid \beta<P\left(f^{-}\left(u_{i}\right) \mid Y\right)<\alpha\right\}$,

(N3') Disagreement (Decision negative region):

$\operatorname{Neg}_{P}^{-}(Y)=\left\{u_{i} \in U \mid P\left(f^{-}\left(u_{i}\right) \mid Y\right) \leq \beta\right\}$.

Both the set of agreed issues $f^{+}\left(u_{i}\right)$ and the set of disagreed issues $f^{-}\left(u_{i}\right)$ contain decision rules in the FRS-CIS over two universes. Therefore, the decision rules in the two set-valued mappings should be considered. For $0 \leq \beta<\alpha \leq 1$, any investor $u_{i} \in U$ and any feasible consensus strategy $Y \in 2^{V}$, the following decision rules are available for the $(0,1)$ probabilistic FRS under FRS-CIS over two universes:

(P4) If $P\left(f^{+}\left(u_{i}\right) \mid Y\right) \geq \alpha$ and $P\left(f^{-}\left(u_{i}\right) \mid Y\right) \leq \beta$, then the investor $u_{i}$ agrees with the feasible consensus strategy $Y$;

(N4) If $P\left(f^{+}\left(u_{i}\right) \mid Y\right) \leq \beta$ and $P\left(f^{-}\left(u_{i}\right) \mid Y\right) \geq \alpha$, then the investor $u_{i}$ disagrees with the feasible consensus strategy $Y$;

(B4) For $u_{i} \in U$ satisfying neither (P4) nor (N4), then the investor $u_{i}$ remains neutral to the feasible consensus strategy $Y$.

Example 3 (Continued from Example 1) The risks of making different decisions can be empirically determined as:

$$
\lambda_{11}=0.35, \lambda_{21}=0.75, \lambda_{31}=0.65, \lambda_{12}=0.8, \lambda_{22}=
$$
$0.12, \lambda_{32}=0.2$.

The loss function satisfies formula (23). By formulas (24) and (25), we have $\alpha=0.6667$ and $\beta=0.4444$.

The following results can be derived from minimum risk decision rules and the principle of three-way decision based on $(0,1)$-probabilistic FRS under the FRS-CIS over two universes:

$\operatorname{Pos}_{P}^{+}(Y)=\emptyset, \operatorname{Bn}_{P}^{+}(Y)=\left\{u_{9}\right\}, \operatorname{Neg}_{P}^{+}(Y)=$ $\left\{u_{1}, u_{2}, u_{3}, u_{4}, u_{5}, u_{6}, u_{7}, u_{8}, u_{10}\right\}$.

$\operatorname{Pos}_{P}^{-}(Y)=\left\{u_{2}, u_{3}, u_{4}, u_{5}, u_{6}, u_{9}\right\}, \operatorname{Bn}_{P}^{-}(Y)=$

$\emptyset, \operatorname{Neg}_{P}^{-}(Y)=\left\{u_{1}, u_{7}, u_{8}, u_{10}\right\}$

According to the above decision rules, no sufferer agrees with the feasible consensus strategy $Y$, sufferers $u_{2}, u_{3}, u_{4}, u_{5}$ and $u_{6}$ disagree with the feasible consensus strategy $Y$, and sufferers $u_{1}, u_{7}, u_{8}, u_{9}$ and $u_{10}$ remain neutral to the feasible consensus strategy $Y$.

\subsection{Three-way decision model of 0.5-probabilistic FRS under FRS-CIS over two universes}

Considering all the information for the FRS-CIS over two universes, 0.5-probabilistic FRS is more accurate than the $(0,1)$-probabilistic FRS in classification. The expected risks and decision rules of 0.5 -probabilistic FRS are similar to those of $(0,1)$-probabilistic FRS.

For $0 \leq \beta<\alpha \leq 1$, any investor $u_{i} \in U$ and any feasible consensus strategy $Y \in 2^{V}$, the following decision rules are available for 0.5 -probabilistic FRS under FRS-CIS over two universes:

(P5) If $P\left(f^{+}\left(u_{i}\right) \mid Y\right) \geq \alpha$ and $P\left(f^{-}\left(u_{i}\right) \mid Y\right) \leq \beta$, then then agent $u_{i}$ agrees with the feasible consensus strategy $Y$;

(N5) If $P\left(f^{+}\left(u_{i}\right) \mid Y\right) \leq \beta$ and $P\left(f^{-}\left(u_{i}\right) \mid Y\right) \geq \alpha$, then then agent $u_{i}$ disagrees with the feasible consensus strategy $Y$;

(B5) For $u_{i} \in U$ satisfying neither (P5) nor (N5), then then agent $u_{i}$ remains neutral to the feasible consensus strategy $Y$.

Example 4 (Continued from Example 2) The risks of 
making different decisions are similar to those in example 3. Therefore, we have $\alpha=0.6667$ and $\beta=0.4444$.

The following results can be derived from minimum risk decision rules and the principle of three-way decision based on 0.5-probabilistic FRS under the FRS-CIS over two universes:

$\operatorname{Pos}_{P}^{+}(Y)=\left\{u_{1}, u_{2}, u_{4}, u_{5}, u_{6}, u_{7}, u_{9}, u_{10}\right\}, \operatorname{Bn}_{P}^{+}(Y)=$ $\left\{u_{8}\right\}, \operatorname{Neg}_{P}^{+}(Y)=\left\{u_{3}\right\}$.

$\operatorname{Pos}_{P}^{-}(Y)=\left\{u_{3}\right\}, \operatorname{Bn}_{P}^{-}(Y)=\emptyset, \operatorname{Neg}_{P}^{-}(Y)=$

$\left\{u_{1}, u_{2}, u_{4}, u_{5}, u_{6}, u_{7}, u_{8}, u_{9}, u_{10}\right\}$.

According to the above decision rules, sufferers $u_{1}, u_{2}, u_{4}, u_{5}, u_{6}, u_{7}, u_{9}$ and $u_{10}$ agree with the feasible consensus strategy $Y$, sufferer $u_{3}$ disagrees with feasible consensus strategy $Y$, and sufferer $u_{8}$ remains neutral to the feasible consensus strategy $Y$.

\section{CONCLUSIONS}

The paper investigates the FRS under the FRS-CIS over two universes, a generalization of the Pawlak's conflict analysis model. Firstly, the investor (patient) and project (symptom) were treated as two independent universes, and two set-valued mappings were established to illustrate the relation between the two universes: $(0,1)$-probabilistic FRS and 0.5 probabilistic FRS under FRS-CIS over two universes. Furthermore, the expected losses and decision rules of the two probabilistic FRSs were derived based on FRS-CIS over two universes. The research results shed new light to solving the FRS under FRS-CIS over two universes. The future research will explore the decision rules of inter-valued and intuition FRS for conflict analysis over two universes.

\section{ACKNOWLEDGMENT}

This work was supported by Sichuan Provincial Science and Technology Program, China (Grant No.: 2019YJ0529) and Key Project of Sichuan Provincial Education Department, China (Grant No.: 18ZA0410). Our thanks go to the anonymous referees and the Editor-in-Chief for their constructive comments that help improve the manuscript.

\section{REFERENCES}

[1] Ramanna, S. (2008). Conflict analysis in the framework of rough sets and granular computing. Handbook of Granular Computing, 1038-1053.

[2] Ramanna, S., Peters, J.F., Skowron, A. (2007). Approaches to conflict dynamics based on rough sets. Fundamenta Informaticae, 75(1-4): 453-468.

[3] Sun, B.Z., Ma, W.M. (2015). Rough approximation of a preference relation by multi-decision dominance for a multi-agent conflict analysis problem. Information Sciences, 315: 39-53. https://doi.org/10.1016/j.ins.2015.03.061

[4] Pawlak, Z. (1998). An inquiry into anatomy of conflicts. Information Sciences, 109(1-4): 65-78. https://doi.org/10.1016/S0020-0255(97)10072-X

[5] Pawlak, Z. (2005). Some remarks on conflict analysis. European Journal of Operational Research, 166(3): 649654. https://doi.org/10.1016/j.ejor.2003.09.038

[6] Zhu, W., Wang, F.Y. (2006). Covering based granular computing for conflict analysis. Lecture Notes in
Computer Science, 3975: 566-571. https://doi.org/10.1007/11760146_58

[7] Liu, S., Wang, J.Y., Lin, H. (2010). Associated-conflict analysis using covering based on granular computing. Lecture Notes in Computer Science, 6328: 297-303. https://doi.org/10.1007/978-3-642-15621-2_33

[8] Lin, T.Y. (2002). Granular computing on binary relations analysis of conflict and Chinese wall security policy. Rough Sets and Current Trends in Computing. Springer Berlin Heidelberg, 296-299. https://doi.org/10.1007/3540-45813-1 38

[9] Lin, T.Y. (2002). Placing the Chinese Walls on the boundary of conflicts-analysis of symmetric binary relations. Computer Software and Applications Conference, COMPSAC 2002. Proceedings. 26th Annual International, Oxford, UK: 966-971. https://doi.org/10.1109/CMPSAC.2002.1045131

[10] Skowron, A., Ramanna, S., Peters, J.F. (2006). Conflict analysis and information systems: a rough set approach. Rough Sets and Knowledge Technology, 4062: 233- 240. https://doi.org/10.1007/11795131 34

[11] Gong, Z.T., Sun, B.Z., Xu, Z.M., Zhang, Z.Q. (2009). The rough set analysis approach to water resources allocation decision in the inland river basin of arid regions(II): The conflict analysis of satisfactions of the decision. International Conference on Machine Learning and Cybernetics. IEEE, Dalian, China, 2009: 1358-1361. https://doi.org/10.1109/ICMLC.2006.258704

[12] Gong, Z.T., Sun, B.Z., Xu, Z.M., Long, A.H. (2005). The rough set analysis approach to water resources allocation decision in the inland river basin of arid regions. Machine Learning and Cybernetics, 2005. Proceedings of 2005 International Conference on. IEEE, pp. 3179-3182. https://doi.org/10.1109/ICMLC.2005.1527490

[13] Herbert, J.P., Yao, J.T. (2011). Game-theoretic rough sets. Fundamenta Informaticae, 108(3- 4): 267-286.

[14] Yao, J.T., Herbert, J.P. (2008). A game-theoretic perspective on rough set analysis. Journal of Chongqing University of Posts Telecommunications: Natural Science Edition, 20(3): 291-298.

[15] Xia, Z.Y., Jiang, Y.C., Zhong, Y.P., Zhang, S.Y. (2004). A novel policy and information flow security model for active network. Intelligence and Security Informatics, Intelligence and Security Informatics. ISI 2004. Lecture Notes in Computer Science, vol 3073. Springer, Berlin, Heidelberg, 3073: 42-45. https://doi.org/10.1007/978-3540-25952-7 4

[16] Deja, R., Ślęak, D. (2001). Rough Set Theory in Conflict Analysis. In: Terano, T., Ohsawa, Y., Nishida, T., Namatame, A., Tsumoto, S., Washio, T. (eds) New Frontiers in Artificial Intelligence. JSAI 2001. Lecture Notes in Computer Science, 2253. Springer, Berlin, Heidelberg.

[17] Zhao, X.R., Hu, B.Q. (2015). Fuzzy and interval-valued fuzzy decision-theoretic rough set approaches based on fuzzy probability measure. Information Sciences, 298: 534-554. https://doi.org/10.1016/j.ins.2014.12.008

[18] Straszecka, E. (2006). Combining uncertainty and imprecision in models of medical diagnosis. Information Sciences, $\quad$ 176(20): 3026-3059. https://doi.org/10.1016/j.ins.2005.12.006

[19] Sun, B.Z., Ma, W.M., Zhao, H.Y. (2016). Rough setbased conflict analysis model and method over two universes. Information Sciences, 372: 111-125. 
https://doi.org/10.1016/j.ins.2016.08.030

[20] Sun, B.Z., Chen, X.T., Zhang, L.Y., Ma, W.M. (2020). Three-way decision making approach to conflict analysis and resolution using probabilistic rough set over two universes. Information Sciences, 507: 809-822. https://doi.org/10.1016/j.ins.2019.05.080

[21] Lang, G.M., Miao, D.Q., Cai, M.J. (2017). Three-way decision approaches to conflict analysis using decisiontheoretic rough set theory. Information Sciences, 406407: 185-207. https://doi.org/10.1016/j.ins.2017.04.030

[22] Lang, G.M., Miao, D.Q., Fujita, H. (2019). Three-way group conflict analysis based on Pythagorean fuzzy set theory. IEEE Transactions on Fuzzy Systems, 28(3): 447-461. https://doi.org/10.1109/TFUZZ.2019.2908123

[23] Lang, G.M. (2019). Three-way decisions-based conflict analysis models. Computer Science, arXiv:1903.03205.

[24] Deja, R. (1996). Conflict model with negotiation. Bulletin of Polish Academic Science, 44(4): 475-498.

[25] Yang, H.L., Liao, X.W., Wang, S.H. (2013). Fuzzy probabilistic rough set model on two universes and its applications. International Journal of Approximate Reasoning, 54(9): $1410-1420$ https://doi.org/10.1016/j.ijar.2013.05.001

[26] Yao, Y.Y., Wong, S.K.W., Lingras, P. (1990). A decision-theoretic rough set model. in: Z.W. Ras, M. Zemankova, M.L. Emrich (Eds.), Methodologies for Intelligent System, North-Holland, New York, 17-24.

[27] Duda, R.O., Hart, P.E., Stork, D.G. (1973). Pattern classification and scene analysis. Wiley Press, New York.

[28] Sun, B.Z., Ma, W.M., Zhao, H.Y. (2016). An approach to emergency decision making based on decisiontheoretic rough set over two universes. Soft Computing, 20(9): 3617-3628. https://doi.org/10.1007/s00500-0151721-6

[29] Yao, Y.Y. (2011). The superiority of three-way decisions in probabilistic rough set models. Information Sciences, 181(6): 1080-1096. 